\title{
Produtividade e podridão parda em couve-flor 'Sharon' influenciadas pela aplicação de nitrogênio e boro
}

\author{
Mônica S de Camargo'; Simone da C Mello²; Dulcinéia Elizabete Foltran'; Quirino Augusto de C \\ Carmello ${ }^{2}$ \\ ${ }^{1}$ APTA Pólo Centro Sul-UPD Tietê, C. Postal 18, 18530-000 Tietê-SP; ${ }^{2}$ USP-ESALQ, C. Postal 9, 13 418-900 Piracicaba-SP; \\ mscamarg@yahoo.com.br
}

\begin{abstract}
RESUMO
A podridão parda é um problema comum em couve-flor que ocasiona sintoma semelhante ao da deficiência de B. Sua ocorrência está associada, especialmente, às adubações com nitrogênio e boro, mas há escassez de informações sobre o problema no Brasil. Neste trabalho avaliou-se o efeito de doses de nitrogênio e épocas de aplicação de boro na produção e na incidência de podridão parda da couveflor 'Sharon'. O experimento foi realizado em Argissolo Vermelho Amarelo de novembro/2005 a fevereiro/2006, com quatro doses de N (100; $150 ; 200$ e $250 \mathrm{~kg} \mathrm{ha}^{-1}$ ) e duas épocas de aplicação de $3 \mathrm{~kg} \mathrm{ha}^{-1} \mathrm{~B}$ (1 e 2 aplicações), além do controle (sem aplicação). O diâmetro das cabeças e a produtividade comercial variaram de 16,45 a 22,03 cm e 15,71 a 29 $\mathrm{t} \mathrm{ha}^{-1}$, respectivamente, e não foram influenciados pelos tratamentos. As doses de $\mathrm{N}$ proporcionaram aumento linear no teor nas folhas e nas cabeças. O caule oco e bronzeamento das cabeças foram reduzidos, enquanto a produtividade comercial aumentou com aplicação de B. Houve correlação negativa entre o teor de $B$ nas folhas $(r=0,66 ; p<0,05)$ e nas cabeças $(r=0,76 ; p<0,05)$ e a incidência de caule oco. A adubação com B para a couve-flor cultivada em solo com teor médio $(0,54 \mathrm{mg}$ de $\mathrm{B} \mathrm{dm}^{-3}$ ) é necessária para reduzir os sintomas da podridão parda. Contudo, mais estudos são necessários em outros solos e cultivares para redução desse distúrbio fisiológico em condições tropicais e melhoria da eficiência da adubação com boro.
\end{abstract}

Palavras-chave: Brassica oleraceae var. botrytis L., bronzeamento das cabeças, solo.

\begin{abstract}
Yield and incidence of hollow stem disorder of cauliflower 'Sharon' influenced by the application of nitrogen and boron

The hollow stem disorder is a common problem in cauliflower, resulting in similar symptoms as those caused by B deficiency. Its occurrence in cauliflower is related to nitrogen and boron levels. There exist little information about this subject in Brazil. The effect of nitrogen rates and boron application periods were evaluated on the cauliflower production and incidence of hollow stem. The experiment was carried out from November 2005 through February 2006 in a Kandiustalf soil $\left(0.54 \mathrm{mg} \mathrm{B} \mathrm{kg}^{-1}, \mathrm{BaCl}_{2} 1.25 \mathrm{mg} \mathrm{L}^{-1}\right)$ at Tietê region, São Paulo State, Brazil, in a randomized complete block design with four replicates, four N levels $\left(100 ; 150 ; 200\right.$ and $\left.250 \mathrm{~kg} \mathrm{ha}^{-1}\right)$ and two periods of $\mathrm{B}$ application (one and two applications) and a control (without application). Cauliflower curd diameter ranged from 16.45 to $22.03 \mathrm{~cm}$ and the commercial yield from 15.71 to $29 \mathrm{t} \mathrm{ha}^{-1}$; these two traits were not influenced by treatments. Nitrogen rates increased linearly in leaves and curds. The hollow stem and curd browning were reduced and commercial yield was increased with B fertilization. The correlation between $B$ concentration on leaves $(r=0.66 ; p<0.05)$ and curds $(\mathrm{r}=0.76 ; \mathrm{p}<0.05)$ with hollow stem disorder was negative. Boron fertilization is necessary to reduce the symptoms of hollow stem when cauliflower is grow in soil with medium B level $(0.54 \mathrm{mg}$ $\mathrm{B} \mathrm{dm}{ }^{-3}$ ). More studies are needed using other types of soil and other cauliflower cultivars in order to reduce this physiological disorder in tropical conditions and increase the efficiency of boron fertilization.
\end{abstract}

Keywords: Brassica oleraceae var. botrytis L., curd browning, soil.

(Recebido para publicação em 6 de dezembro de 2007; aceito em 20 de fevereiro de 2009)

(Received in December 6, 2007; accepted in February 20, 2009)

$\mathrm{E}^{\mathrm{n}}$ ntre as brassicáceas, a couve-flor é uma das mais comercializadas no estado de São Paulo (FNP, 2005), sendo rentável para os produtores, especialmente na entressafra. É exigente em nutrientes, merecendo destaque o nitrogênio e boro, especialmente para o aumento de produção e de qualidade.

Embora a demanda por nitrogênio seja alta, os sintomas de deficiência em campo não são comumente encontrados como aqueles provenientes do boro. A deficiência de B ocasiona pontuações de coloração bronzeada e caule oco, sintomas semelhantes àqueles da podridão parda (Everaarts \& Putke, 2003).
A podridão parda em brássicas ainda não está totalmente esclarecida, podendo ocorrer mesmo quando o $\mathrm{B}$ é fornecido em quantidade suficiente ou está com teor adequado no solo (Shelp et al.,1995). A ocorrência desse distúrbio causa problemas sérios de qualidade do produto. É influenciada por altas temperaturas, umidade (Scaife \& Wur, 1990), tipo de solo, cultivares (Shattuck \& Shelp, 1987), nitrogênio e boro (Batal et al., 1997). Embora a maioria dos estudos seja realizada com esses nutrientes, os resultados são contraditórios e escassos em condições tropicais. Aliado a isso, pouco se sabe sobre as cultivares utilizadas no País.

A maioria dos trabalhos mostra aumento da incidência de caule oco com doses elevadas de nitrogênio em couve-flor (Cutcliffe, 1972; Gorski \& Armstrong, 1985). Para brócolis, Tremblay (1989), utilizando doses de $\mathrm{N}$ $\left(75,150\right.$ e $\left.225 \mathrm{~kg} \mathrm{ha}^{-1} \mathrm{~N}\right)$, obteve maior crescimento vegetativo e volume do caule oco com a maior dose aplicada. Babik \& Elkner (2002) também verificaram que doses de 400 a $600 \mathrm{~kg} \mathrm{ha}^{-1} \mathrm{~N}$ aumentaram a altura, a massa fresca da planta e também a incidência de caule oco. 
A aplicação de até $4,48 \mathrm{~kg} \mathrm{ha}^{-1}$ de B em solos com teores de 0,34 a $0,46 \mathrm{mg}$ $\mathrm{dm}^{-3}$ deste nutriente, não reduziu a incidência de caule oco em couve-flor, brócolis e couve-de-Bruxelas (Gupta \& Cutcliffe, 1973), ocorrendo situação similar com aplicação de até $8 \mathrm{~kg} \mathrm{ha}^{-1} \mathrm{de} \mathrm{B}$ em brócolis (Pizetta et al., 2005). Gupta \& Cutcliffe (1975) também mostraram que a podridão parda não estava relacionada com baixo teor de $\mathrm{B}\left(0,28 \mathrm{mg} \mathrm{kg}^{-1}\right)$ no solo ou no tecido (>10,5 $\left.\mathrm{mg} \mathrm{kg}^{-1} \mathrm{~B}\right)$. Por outro lado, Pizetta et al. (2005) observaram redução dos sintomas de podridão parda em couve-flor 'Júlia', cultivada em solo de textura média $\left(0,15 \mathrm{mg} \mathrm{de} \mathrm{B} \mathrm{dm}^{-3}\right)$, com adição de $2 \mathrm{~kg} \mathrm{ha}^{-1} \mathrm{de}$ B. Essa redução também foi observada por Mello et al. (1997) para cultivares de brócolis em solo de textura média( $\left.1 \mathrm{mg} \mathrm{de} \mathrm{B} \mathrm{kg}^{-1}\right)$ com aplicação de 2,16 kg de B ha- .

Quanto à aplicação conjunta de nitrogênio e boro, Everaarts \& Putter (2000) observaram que $2 \mathrm{~kg}$ de $\mathrm{B} \mathrm{ha}^{-1}$ não influenciou a ocorrência de podridão parda, enquanto a aplicação de $\mathrm{N}$ resultou no seu aparecimento em couve-flor. A aplicação de 2 e $4 \mathrm{~kg}$ de B ha ${ }^{-1}$ com doses de $90 \mathrm{~kg}$ de $\mathrm{N}^{-1}$ não influenciou os sintomas da podridão parda (Vigier \& Cutcliffe, 1987). Ao contrário disso, Batal et al. (1997) constataram redução da podridão parda em couveflor com $269 \mathrm{~kg}$ de $\mathrm{N} \mathrm{ha}^{-1}$ e $8,8 \mathrm{~kg}$ de B ha ${ }^{-1}$ em solo argiloso $\left(0,21 \mathrm{mg} \mathrm{de} \mathrm{B} \mathrm{kg}^{-1}\right)$ e arenoso $\left(0,07 \mathrm{mg} \mathrm{de} \mathrm{B} \mathrm{kg}^{-1}\right)$.

Considerando a importância da cultura e a escassez de informações sobre o assunto em condições tropicais, objetivou-se avaliar os efeitos de doses de nitrogênio e de formas de aplicação de $\mathrm{B}$ na produtividade e ocorrência de podridão parda em couve-flor no verão na região de Tietê (SP).

\section{MATERIAL E MÉTODOS}

O experimento foi realizado na fazenda da APTA Centro Sul-UPD de Tietê, em blocos casualizados com quatro repetições, estudando-se quatro doses de $\mathrm{N}\left(100 ; 150 ; 200\right.$ e $\left.250 \mathrm{~kg} \mathrm{ha}^{-1}\right)$ na forma de nitrato de amônio e épocas de aplicação de $\mathrm{B}$ na dose de $3 \mathrm{~kg} \mathrm{ha}^{-1}$ : controle (sem aplicação); uma aplicação; duas aplicações. A dose de B foi aplicada totalmente no plantio (uma aplicação) e dividida entre plantio e época de formação das cabeças, utilizando Boromol ( $8 \%$ B e $0,8 \%$ Mo).

A análise química inicial do Argissolo Vermelho Amarelo revelou: $\mathrm{MO}=14 \mathrm{~g}$ $\mathrm{dm}^{-3} ; \mathrm{P}($ resina $)=7 \mathrm{mg} \mathrm{dm}^{-3} ; \mathrm{K}, \mathrm{Ca}$ e $\mathrm{Mg}=$ 3,$1 ; 24$ e $11 \mathrm{mmol}_{\mathrm{c}} \mathrm{dm}^{-3} ; \mathrm{pH}\left(\mathrm{CaCl}_{2}\right)=4,9$; $\mathrm{SB}=38,1 \mathrm{mmol}_{\mathrm{c}} \mathrm{dm}^{-3} ; \mathrm{CTC}=60,1 \mathrm{mmol}$ 。 $\mathrm{dm}^{-3} ; \mathrm{V}=63 \% ; \mathrm{m}=3 \%$, conforme Raij et al. (1997) e B=0,54 $\mathrm{mg} \mathrm{dm}^{-3}$.

A calagem foi feita 60 dias antes do plantio, baseando-se na análise química do solo para elevar a saturação por bases para $80 \%$. A adubação de plantio foi feita em sulcos, totalizando $60 \mathrm{~kg}$ de $\mathrm{N}$ ha $^{-1}$ por ciclo (uréia, $45 \%$ de N), $600 \mathrm{~kg}$ de $\mathrm{P}_{2} \mathrm{O}_{5}$ ha $^{-1}$ (superfosfato simples, $18 \%$ $\mathrm{P}_{2} \mathrm{O}_{5}$ ) e $120 \mathrm{~kg} \mathrm{de}_{2} \mathrm{O} \mathrm{ha}^{-1}(\mathrm{KCl}, 60 \%$ $\mathrm{K}_{2} \mathrm{O}$ ), segundo Trani et al. (1997).

Após o preparo do solo e adubações, foram aplicados os tratamentos com boro em cada cova uma semana antes do plantio. As mudas de couve-flor 'Sharon' foram plantadas em 21/10/05 no espaçamento de 1,0 entre linhas e $0,5 \mathrm{~m}$ entre plantas, totalizando 20.000 plantas por ha. Cada parcela foi composta de 20 plantas, distribuídas em 4 linhas de plantio, sendo utilizada como parcela útil 10 plantas das duas linhas centrais. As doses de $\mathrm{N}$ dos tratamentos foram divididas em 25,25 e $50 \%$ aos 15,30 e 45 dias após o transplantio das mudas.

A irrigação foi feita via aspersão e as capinas para controle de plantas daninhas no primeiro mês a cada 15 dias e, a partir disso, a cada 30 dias. A colheita foi iniciada em 27/01, estendendo-se até 23/02/06, onde foram anotados o ciclo (dias do transplantio até colheita) e avaliadas a massa fresca e o diâmetro das cabeças, quantificadas as plantas com caule oco e bronzeamento das cabeças para cada planta da parcela útil. A produtividade total e comercial (produtividade de plantas sem podridão parda) foram calculadas a partir dos dados de massa fresca das cabeças.

Para avaliação dos teores de nitrogênio e boro, foram coletadas seis folhas recém-maduras por parcela aos 58 dias, no início da formação das cabeças. $\mathrm{Na}$ colheita, após as avaliações das cabeças, elas foram divididas em quatro partes iguais, sendo colocada uma parte em sacos de papel. As folhas e cabeças foram levadas para estufa com cir- culação forçada de ar a $65^{\circ} \mathrm{C}$ até atingir massa constante. Ao final da secagem, as cabeças foram reunidas em uma amostra por parcela. O material seco foi passado em moinho tipo Willey e feita a determinação do N (Malavolta et al.,1997) e B (Bataglia et al.,1983).

No fim das colheitas, foram coletadas amostras de solo na camada de 0 a $20 \mathrm{~cm}$ para avaliação do teor de $\mathrm{B}\left(\mathrm{BaCl}_{2} 2 \mathrm{H}_{2} \mathrm{O}\right.$ 0,125\%), microondas (Abreu et al.,1994).

As variáveis foram analisadas pelo teste F para análise de variância, sendo, posteriormente, avaliadas as épocas de aplicação de B pelo teste de Tukey e as doses de $\mathrm{N}$ pela análise de regressão polinomial, segundo Nogueira (1997) utilizando o programa SAS (SAS Institute, 1996).

\section{RESULTADOS E DISCUSSÃO}

As doses de nitrogênio e as épocas de aplicação de boro apresentaram efeitos significativos independentes, variando com produtividade total e comercial, precocidade, diâmetro das cabeças, caule oco, bronzeamento de plantas e teor de nitrogênio e boro nas folhas e cabeças.

As doses de $\mathrm{N}$ influenciaram o teor de $\mathrm{N}$ nas folhas e nas cabeças de couve-flor. Houve aumento linear dos teores foliares de nitrogênio com as doses utilizadas (Figura 1a), mas não atingiram valores considerados adequados (40 a $60 \mathrm{~g} \mathrm{de}^{\mathrm{N} \mathrm{kg}}{ }^{-1}$ ) segundo Trani et al. (1997). Isso pode ser devido à terceira parcela da adubação nitrogenada ter sido aplicada aos 45 dias e o período de coleta das folhas ter ocorrido aos 58 dias. Entretanto, as plantas apresentaram valores médios satisfatórios para massa fresca, diâmetro e produtividade total: $0,945 \mathrm{~kg}, 21,50 \mathrm{~cm}$ e $18,78 \mathrm{tha}^{-1}$, respectivamente. Aliado a isso, na colheita, o valor máximo estimado nas cabeças (40 $\mathrm{g}_{\text {de }} \mathrm{N} \mathrm{kg}^{-1}$ ) foi obtido com $213 \mathrm{~kg}$ de $\mathrm{N}$ ha $^{-1}$ (Figura $1 b$ ), inferior à maior dose utilizada.

A massa fresca, diâmetro, produtividade total e comercial, ocorrência de caule oco e de bronzeamento nas cabeças e precocidade da colheita não foram alterados pelas doses de N. A ausência de resposta à adubação nitrogenada pode ser explicada pela lixiviação do $\mathrm{N}$ 


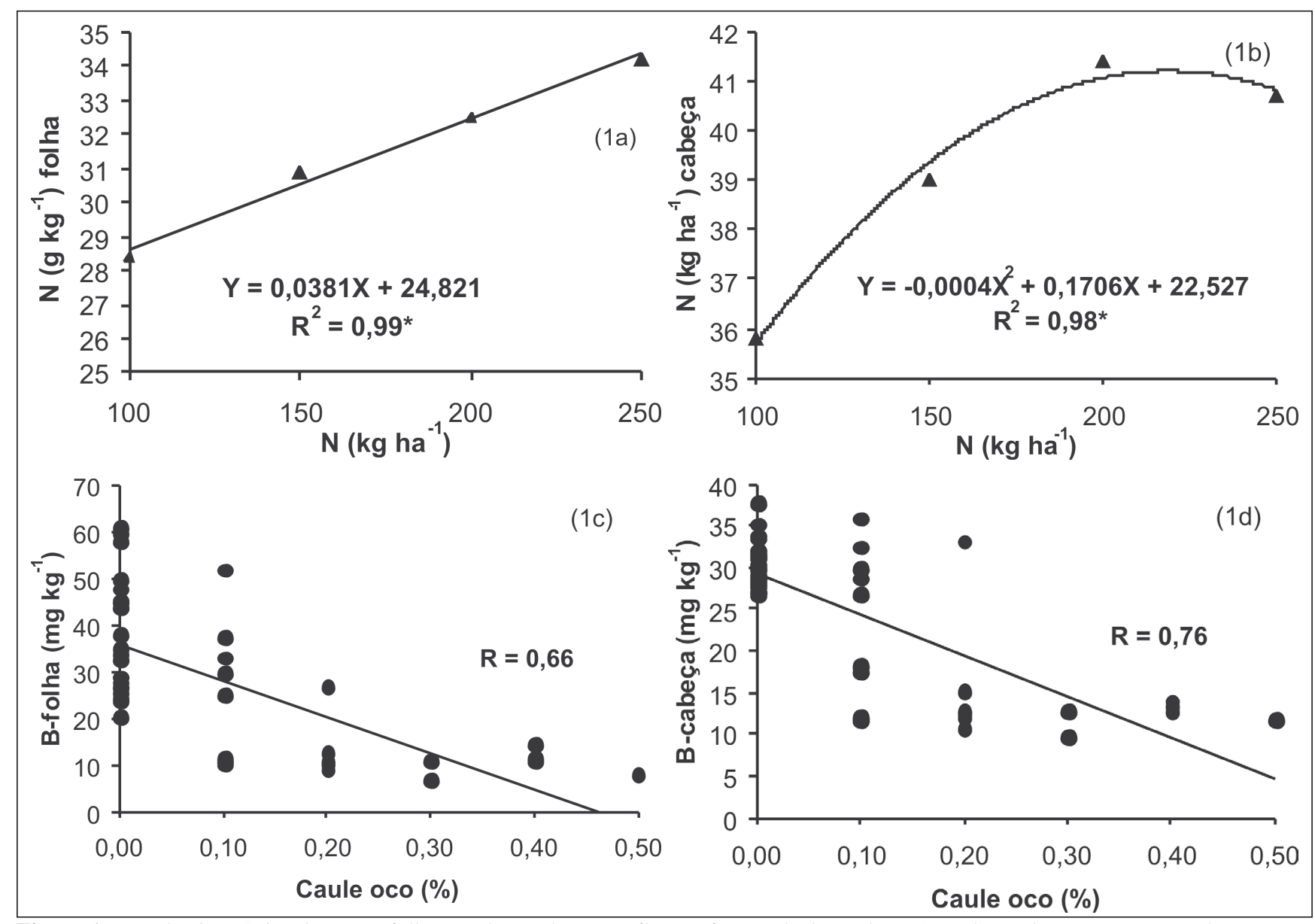

Figura 1. Teor de nitrogênio e boro nas folhas e cabeças de couve-flor em função de doses de N (1a e 1b) e relação entre B e caule oco (1c e $1 \mathrm{~d}$ ); *significativo $\mathrm{p}<0,05$ (nitrogen and boron concentration in leaves and curds of cauliflower as affected by rates of $\mathrm{N}$ (1a and $1 \mathrm{~b}$ ) and relashionship between B and hollow stem (1c and 1d); significant p<0.05). Tietê, APTA Pólo Centro Sul, 2006-2007.

abaixo da zona radicular das plantas devido à textura arenosa do solo e às precipitações ocorridas durante o ciclo de cultivo, que totalizaram $695 \mathrm{~mm}$ ao final do ciclo (Figura 2), além da irrigação. Scaife \& Wur (1990) também não obtiveram variação do diâmetro e massa fresca das cabeças de couve-flor com até $225 \mathrm{~kg}_{\text {de N ha }}{ }^{-1}$, ao contrário de Batal et al. (1997), que utilizaram doses até 381 $\mathrm{kg}$ de $\mathrm{N} \mathrm{ha}^{-1}$. A aplicação de até $224 \mathrm{~kg}$ de $\mathrm{N} \mathrm{ha}^{-1}$ não alterou a precocidade da colheita da couve-flor (Cutcliffe \& Munro, 1976; Nilson,1980) e a adubação nitrogenada (200 a $600 \mathrm{~kg}$ de $\mathrm{N} \mathrm{ha}^{-1}$ ) adiantou o período de maturidade das cabeças de brócolis (Babik \& Elkner, 2002).

O fornecimento de B, por sua vez, não influenciou a produtividade total, a massa e o diâmetro das cabeças (Tabela 1), concordando com os resultados de Gupta \& Cutcliffe (1973). A utilização de
$2,16 \mathrm{~kg}$ de $\mathrm{B} \mathrm{ha}{ }^{-1}$, não afetou a produtividade total de brócolis 'Baccus' e 'Futura' (Mello et al., 1997). Ao contrário, a máxima produtividade de couve-flor (30 $\mathrm{t} \mathrm{ha}^{-1}$ ) foi obtida com 5,5 $\mathrm{kg} \mathrm{ha}^{-1}$ de B (Pizetta et al., 2005).

A aplicação parcelada de $B$ reduziu o tempo de colheita em 3,2 dias quando comparado com a testemunha, a qual não diferiu da adubação total no plantio (Tabela 1). Isso pode ser devido à sua maior disponibilidade do micronutriente no solo no período de maior exigência da cultura no tratamento com adubação parcelada de B. A alta intensidade de chuvas (695 $\mathrm{mm}$ no período), associada à textura do solo, podem ter favorecido a lixiviação de $\mathrm{B}$ quando a adubação foi feita apenas no plantio. Assim, no período de formação da cabeça, quando é grande a exigência desse nutriente, o seu teor apresentou-se mais alto no solo para o tratamento com adubação parce- lada, propiciando maior disponibilidade às plantas (Tabela 2).

Embora os teores foliares de B aos 45 dias (início da formação da cabeça) tenham sido maiores no tratamento com $3 \mathrm{~kg} \mathrm{ha}^{-1}$ de B no plantio (Tabela 2), os tratamentos com boro estavam dentro da faixa considerada adequada ( 30 a 80 $\mathrm{mg} \mathrm{kg}^{-1}$ ) segundo Trani et al. (1997).

$\mathrm{O}$ teor de $\mathrm{B}$ na cabeça aumentou com a aplicação do nutriente, independente da época de aplicação (Tabela 2). Houve correlação negativa entre os teores de $B$ nas folhas $(r=0,66 ; p<0,05)$ e nas cabeças $(r=0,76 ; p<0,05)$ com a incidência de caule oco (Figuras 1c e 1d). A produtividade comercial, por sua vez, aumentou com o fornecimento de $\mathrm{B}$, pois esse nutriente reduziu a incidência de caule oco e de bronzeamento na cabeça, sintomas que inviabilizam a comercialização da couve-flor (Tabela 1). Esses resultados evidenciam que o 
Tabela 1. Produtividade total e comercial, precocidade, diâmetro das cabeças, porcentagem de caule oco e bronzeamento e de plantas não comerciais de couve-flor 'Sharon’ em função de épocas de aplicação de B (total and commercial yield, precocity, curd diameter, percentage of hollow stem and curd browning and non-commercial plants of 'Sharon' cauliflower' as affect by of B application period). Tietê, APTA Pólo Centro Sul, 2006-2007.

\begin{tabular}{|c|c|c|c|c|c|c|c|}
\hline \multirow{2}{*}{$\begin{array}{l}\text { Época de } \\
\text { aplicação } \\
\left(\mathrm{kg} \mathrm{ha}^{-1}\right)\end{array}$} & \multirow{2}{*}{$\begin{array}{c}\text { Massa de } \\
\text { cabeças } \\
\left(\mathrm{kg} \mathrm{ha}^{-1}\right)\end{array}$} & \multicolumn{2}{|c|}{ Produtividade $\left(\mathrm{kg} \mathrm{ha}^{-1}\right)$} & \multirow{2}{*}{$\begin{array}{l}\text { Precocidade } \\
\text { (dias) }\end{array}$} & \multirow{2}{*}{ Diâmetro $(\mathrm{cm})$} & \multirow{2}{*}{ Caule oco (\%) } & \multirow{2}{*}{$\begin{array}{c}\text { Bronzeamento } \\
(\%)\end{array}$} \\
\hline & & Total & Comercial & & & & \\
\hline Testemunha & 0,996 a & $18362,30 \mathrm{a}$ & $7432,00 \mathrm{~b}$ & $77,94 \mathrm{a}$ & 21,06 a & $36,90 \mathrm{a}$ & $30,60 a$ \\
\hline 2 aplicações & 0,932 a & $18628,70 \mathrm{a}$ & $16180,00 \mathrm{a}$ & $74,74 \mathrm{~b}$ & 21,55 a & $2,50 \mathrm{~b}$ & $10,60 \mathrm{~b}$ \\
\hline 1 aplicação & $0,919 a$ & $19362,20 \mathrm{a}$ & $15890,00 \mathrm{a}$ & $77,31 \mathrm{a}$ & 21,79 a & $7,50 \mathrm{~b}$ & $15,60 \mathrm{~b}$ \\
\hline$\overline{C V}$ & 12,47 & 14,12 & 20,00 & 3,84 & 12,00 & 18,20 & 20,54 \\
\hline$\overline{D M S}$ & 0,1027 & 2301,70 & 3875,5 & 2,55 & 0,95 & 14,29 & 15,79 \\
\hline
\end{tabular}

*Médias seguidas da mesma letra na coluna não diferem entre si pelo Teste Tukey $(\mathrm{p}<0,05)$ (means followed by the same letter in the column did not differ from each other by Tukey test $(\mathrm{p}<0.05)$.

fornecimento de B para a couve-flor cultivada em solo com teor médio do nutriente $\left(0,54 \mathrm{mg} \mathrm{dm}^{-3}\right)$ é necessário para reduzir esses sintomas.

A redução da incidência do caule oco com a utilização do boro, constatada no presente experimento, concorda com os resultados de Batal et al. (1997) e Pizetta et al. (2005), que aplicaram doses de boro de $8,8 \mathrm{~kg} \mathrm{ha}^{-1}$ e $2 \mathrm{~kg} \mathrm{ha}^{-1}$, respectivamente. Essa redução também foi observada por Mello et al. (1997) em cultivares de brócolis em solo de textura média (1 $\mathrm{mg} \mathrm{de} \mathrm{B} \mathrm{kg}^{-1}$ ) com 2,16 $\mathrm{kg} \mathrm{ha}^{-1} \mathrm{~B}$.

Por outro lado, Gupta \& Cutcliffe (1973), com a aplicação de até $4,48 \mathrm{~kg} \mathrm{ha}^{-1}$ de $B$, não obtiveram a redução na incidência do distúrbio em couve-flor e brócolis, assim como Pizetta et al. (2005) com aplicação de até $8 \mathrm{~kg} \mathrm{de} \mathrm{B} \mathrm{ha}{ }^{-1} \mathrm{em}$ brócolis. Aliado a isso, Gupta \& Cutcliffe(1975) demonstraram ausência de correlação entre a podridão parda e o teor de B no solo $\left(0,28 \mathrm{mg} \mathrm{kg}^{-1}\right)$ ou na planta $\left(>10,5 \mathrm{mg} \mathrm{kg}^{-1} \mathrm{~B}\right)$, assim como Shattuck \& Shelp (1987) para brócolis. Isso pode ser devido à limitação da análise de $\mathrm{B}$ na folha, pois pode ocorrer redistribuição do B em algumas cultivares (Scaife \& Wur,1990), sendo importante também sua avaliação nas inflorescências.

A diferença entre cultivares de brócolis quanto à sua mobilidade de redistribuição de boro também foi sugerida por Shelp et al. (1995) para brócolis. Aliado a isso, as cultivares podem apresentar diferenças quanto à capacidade de absorção de boro, conforme mostraram Mello et al. (1997). Da mesma forma que ocorrem diferenças entre cultivares de brócolis, isso poderia ocorrer para couve-flor.

Tabela 2. Teor de nitrogênio e boro na folha recém madura (início do florescimento) e na cabeça da couve-flor 'Sharon' em função de épocas de aplicação de B (nitrogen and boron concentration on newly mature leaf (beginning of flowering) and curd of 'Sharon' cauliflower in function of B application period). Tietê, APTA Pólo Centro Sul, 2006-2007.

\begin{tabular}{|c|c|c|c|c|c|c|}
\hline \multirow{2}{*}{$\begin{array}{l}\text { Épocas de } \\
\text { aplicação } \\
\left(\mathrm{kg} \mathrm{ha}^{-1}\right)\end{array}$} & \multicolumn{2}{|c|}{ Folhas $\left(\mathbf{g ~ k g}^{-1}\right)$} & \multicolumn{2}{|c|}{ Cabeças $\left(\mathrm{g} \mathrm{kg}^{-1}\right)$} & \multicolumn{2}{|c|}{ Solo } \\
\hline & $\mathbf{N}$ & B & $\mathbf{N}$ & B & $\begin{array}{c}B \\
\left(\mathrm{mg} \mathrm{dm}^{-3}\right)\end{array}$ & $\mathrm{pH}$ \\
\hline Testemunha & $30,00 \mathrm{~b}$ & $10,62 \mathrm{c}$ & $40,15 a$ & $13,21 b$ & $0,17 \mathrm{~b}$ & $4,87 \mathrm{a}$ \\
\hline 2 aplicações & $31,27 a b$ & $28,89 \mathrm{~b}$ & $38,56 \mathrm{a}$ & $30,34 a$ & $0,97 \mathrm{a}$ & $4,87 \mathrm{a}$ \\
\hline 1 aplicação & 33,19 a & $45,09 \mathrm{a}$ & $38,96 \mathrm{a}$ & $30,42 \mathrm{a}$ & $0,31 \mathrm{~b}$ & $5,06 \mathrm{a}$ \\
\hline$\overline{\mathrm{CV}}$ & 11,61 & 21,49 & 11,03 & 9,79 & 22,32 & 5,69 \\
\hline$\overline{\mathrm{DMS}}$ & 3,17 & 5,24 & 3,75 & 2,09 & 0,19 & 0,24 \\
\hline
\end{tabular}

*Médias seguidas da mesma letra na coluna não diferem entre si pelo Teste Tukey $(\mathrm{p}<0,05)$ (Mmeans followed by the same letter at column did not differ from each other by Tukey test $(\mathrm{p}<0.05))$.

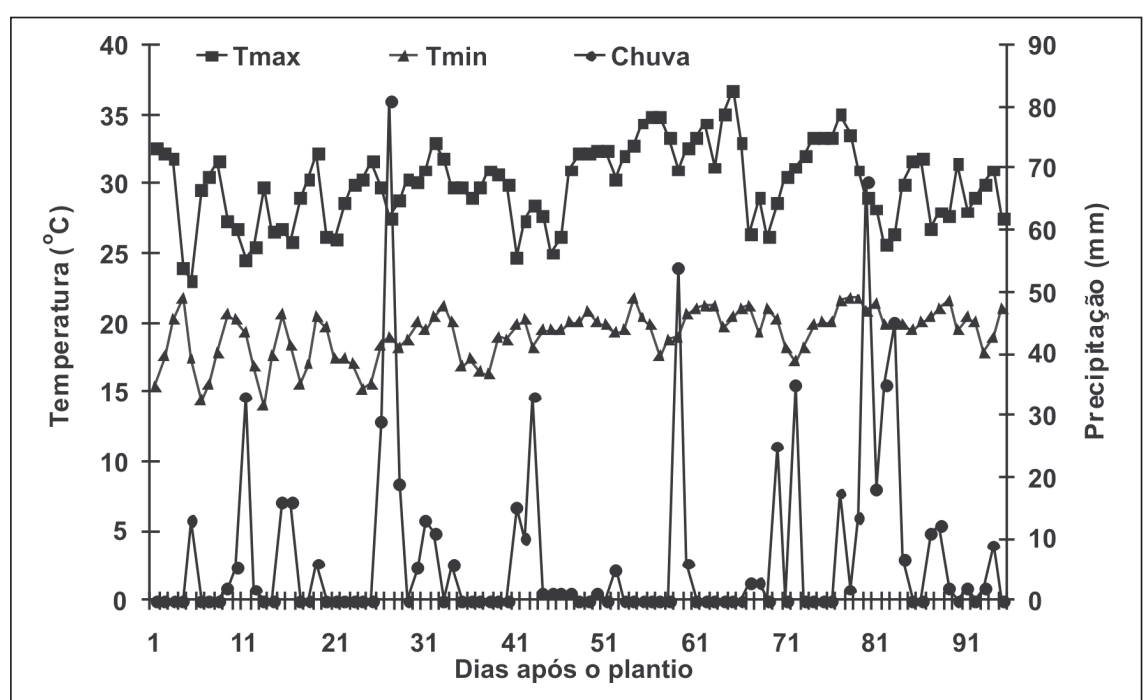

Figura 2. Temperaturas máximas e mínimas e precipitação durante o experimento (maximum and minimum temperatures and precipitation during experiment period). Tietê, APTA Pólo Centro Sul, 2006-2007.

De acordo com os resultados obtidos no presente trabalho, a adubação com nitrogênio com doses até $250 \mathrm{~kg}$ de
$\mathrm{N} \mathrm{ha}^{-1}$ em cobertura não influenciou a podridão parda da couve-flor 'Sharon' e a adubação com $B$, independentemente 
da época de aplicação reduziu a podridão parda da couve-flor 'Sharon' cultivada em solo com teor médio $(0,54 \mathrm{mg}$ de $\left.\mathrm{B} \mathrm{dm}^{-3}\right)$.Entretanto, mais estudos são necessários em outros solos e cultivares para redução desse distúrbio fisiológico em condições tropicais e melhoria da eficiência da adubação com boro.

\section{REFERÊNCIAS}

ABREU CA; ABREU MF; RAIJ B.V; BATAGLIA O; ANDRADE JC. 1994. Extraction of boron from soil by microwave heating for ICP-AES determination. Communications in Soil Science and Plant Analysis 25: 3321-3333.

BABIK I; ELKNER K. 2002. The effect of nitrogen fertilization and irrigation on yield and quality of broccoli. Acta Horticulturae 571: 33-43.

BATAGLIA O; FURLANI AMC; TEIXEIRA JPF; FURLANI PR; GALLO, JR. 1983. Métodos de análise química de plantas. Campinas: Instituto Agronômico. 48 p. (Boletim Técnico, 78).

BATAL KM; GRANBERRY DM; MULLINIX JR BG. 1997. Nitrogen, magnesium, and boron applications affect cauliflower yield, curd mass, and hollow stem disorder. HortScience 32: 75-78.

CUTCLIFFE JA. 1972. Effects of plant spacing and nitrogen on incidence of hollow stem in broccoli. Canadian Journal of Plant Science 52: 833-834.

CUTCLIFFE JA; MUNRO DC. 1976. Effects of nitrogen, phosphorus and potassium on yield and maturity of cauliflower. Canadian Journal of Plant Science 56: 127-131.
EVERAARTS AP; PUTTER H. 2000. Fast growth results in more hollow stems in cauliflower. PAV Bulletin Bollegrondsroenteteelt 2: 4-6.

EVERAARTS AP; PUTKE H. 2003. Hollow stem in cauliflower. Acta Horticulturae, 607: 187-190.

FNP. 2005. Anuário da Agricultura Brasileira. São Paulo: FNP Consultoria, 360p.

GORSKI SF; ARMSTRONG DM. 1985. The influence of spacing and nitrogen rate on yield and hollow stem in broccoli. Ohio Agricultural Research Development Center Research Circular 288: 16-18.

GUPTA UC; CUTCLIFFE JA. 1975. Boron deficiency cole crops under field and greenhouse conditions. Communication Soil Science Plant Analysis 6: 181-188.

GUPTA UC; CUTCLIFFE JA. 1973. Boron nutrition of broccoli, Brussels sprouts and cauliflower on Prince Edward Island soils. Canadian Journal of Soil Science 53: 275279.

MALAVOLTA E; VITTI GC; OLIVEIRA AS. 1997. Avaliação do estado nutricional das plantas: princípios e aplicações. $2^{\mathrm{a}}$ ed. Piracicaba: Potafós, p.231-305.

MELLO SC; CASTELLANE PD; CORTEZ GEP. 1997. Influência do boro no desenvolvimento e na produtividade de cultivares de brócolis (Brassica oleraceae var. itálica). Científica 25: 269-277.

NILSON T. 1980. The influence of soil type, nitrogen and irrigation on yield, quality and chemical composition of cauliflower. Swedish Journal of Agricultural Research 10: 76-75.

NOGUEIRA MCS. 1997. Estatística experimental aplicada à experimentação agronômica. Piracicaba : ESALQ-Depto Matematica e Estatistica, 250 p.
PIZETTA LC; FERREIRA ME; CRUZ MCP; BARBOSA JC. 2005. Resposta de brócolis, couve-flor e repolho à adubação com boro em solo arenoso. Horticultura Brasileira 23: 51-56.

RAIJ B van; CANTARELLA H; QUAGGIO JA; FURLANI AMC (Ed). 1997. Recomendações de adubação e calagem para o estado de São Paulo. Campinas: Instituto Agronômico/Fundação IAC. (Boletim Técnico, 100).

SCAIFE A; WURR DCE. 1990. Effects of nitrogen and irrigation on hollow stem of cauliflower (Brassica oleraceae var. botrytis). Journal of Horticultural Science 65: 25-29.

SHATTUCK VI; SHELP BJ. 1987. Effect of boron nutrition on the incidence of hollow stem in broccoli. Canadian Journal Plant Science 67: 1221-1225.

SHELP BJ; MARENTES E; KITHEKA AM; VIVEKANANDAM P. 1995. Boron mobility in plants. Physiologia Plantarum 94:356-396.

TRANI PE; PASSOS FA; AZEVEDO JA; TAVARES M. 1997. Brócolos, couve-flor e repolho. In: RAIJ B van; CANTARELLA H; QUAGGIO JA; FURLANI AMC. (Eds.) Recomendações de adubação e calagem para o estado de São Paulo. $2^{\mathrm{a}}$ ed. Campinas: Instituto Agronômico/Fundação IAC. p.175. (Boletim Técnico, 100).

TREMBLAY N. 1989. Effect of nitrogen sources and rates on yield and hollow stem development in broccoli. Canadian Journal of Plant Science 69: 1049-1053.

VIGIER B; CUTCLIFFE JA. 1987. Effect of boron and nitrogen on the incidence of hollow stem in broccoli. Acta Horticulturae 157: 303-308.

SAS Institute INC. 1996. The SAS-system for windows: release 6.11(software). Cary: SAS Institute. 